\title{
Derecho a la ciudad, producción social y gestión participativa del hábitat. La pro- moción de iniciativas comunitarias incluyentes en la Ciudad de México* Enrique Ortiz**
}

\section{Resumen}

Se realiza un primer acercamiento al contexto global, donde palabras como dominación, explotación o depredación confluyen en el cuestionamiento de la viabilidad misma del mundo que estamos construyendo (crisis financiera, ambiental, energética, alimentaria, etc.). En segundo lugar, en el contexto regional latinoamericano, se plantean tres temas estratégicos: el derecho a la ciudad, la producción social del hábitat y la gestión participativa del hábitat. Se presenta por un lado la experiencia integradora que están llevando a cabo diferentes organizaciones del movimiento urbano popular consistente, entre otras cosas, en la elaboración y suscripción de la Carta de la Ciudad de México por el Derecho a la Ciudad. Por otro lado se muestran tres experiencias concretas - La Cooperativa Unión de Palo Alto, Barrio Cananea y Conjunto Autogestionario El Capulín - dedicadas desde hace mas de tres décadas a la producción y la gestión participativa del hábitat en el Estado de México. Son tres referentes históricos para la instauración de un sistema público de apoyo a la producción social y a la gestión participativa del hábitat, que además ponga el acento en sistematizar, con las nuevas herramientas de las que disponemos, los procesos de gestión de los organismos públicos para hacerlos capaces de administrar con eficacia la complejidad.

\section{Palabras clave}

Producción social del hábitat; Gestión social del hábitat; Derecho a la ciudad; Participación ciudadana.

\section{Abstract: Right to the city, social production and participative management of habitat. The promotion of inclusive community initiatives in Mexico City}

An approach to the global context is first taken, where words such as domination, exploitation and predation converge in the questioning of the very viability of the world we are building (financial crisis, environmental crisis, energy crisis, food crisis, etc). In the second place, in the regional Latin American context, three strategic issues are considered: the right to the city, the social production of habitat, and the participatory management of habitat. On one hand, there is the experience of integration which is being implemented by organizations of popular urban movement consisting of, among other things, the preparation and signing of the Mexico City Charter for the Right to the City. On the other hand, three specific experiences are shown: the Cooperative Union of Palo Alto, Barrio Cananea, and the Self-Governing Group El Capulin, which have been dedicated to the production and participative management of habitat for more than three decades in the State of Mexico. These are three historical references for the establishment of a public system of support for the social production and participative management of habitat, which also pays attention to systematizing, with the new tools at our disposal, the processes of management of public institutions to enable them to manage complexity effectively.

\section{Key words}

Social Production of Habitat; Social Management of Habitat; Right to the City; Citizen Participation.

\footnotetext{
Recibido: 13/09/2010; aceptado: 15/10/2010

* El texto de este artículo corresponde a la transcripción de la conferencia internacional -con el mismo título- sobre urbanización y desarrollo comunitario en China en la globalización (Shangai, China, junio de 2009).

** Arquitecto. Miembro y ex presidente de Coalición Internacional para el Hábitat (HIC). E-mail: hic-al@hic-al.org.
} 


\section{Contexto global}

Estamos inmersos en un tiempo de cambios profundos en las ideas, la tecnología, el modo de producción de los bienes materiales y las formas de relacionarse y de comunicarse.

Tiempo contradictorio y paradójico en el que las tendencias a la acumulación y la concentración del poder económico y el imperio global de las grandes corporaciones incentivan nuevas respuestas sociales, tecnológicas, productivas, espirituales, políticas y artísticas surgidas desde los lugares y la gente.

Por un lado se consolidan nuevas formas de dominación más abstractas y lejanas, que cuestionan la soberanía de los Estados y que impulsan procesos de crecimiento que se hacen a costa de la depredación de la naturaleza y de la explotación extrema de la gente.

Procesos acelerados, tanto por el desorden monetario causado por la falta de valor real de la mayor parte del dinero con el que se especula globalmente a gran escala, a costa de las economías más débiles, como por otros factores que confluyen en las múltiples situaciones críticas que hoy ponen en cuestionamiento la viabilidad misma del mundo que estamos construyendo: crisis financiera, que impacta ya gravemente en muchos campos de la economía global; crisis ambiental; crisis energética; crisis alimentaria; crisis del agua; crisis de producción (se producen y mercantilizan masivamente bienes superfluos y se cancelan posibilidades a la producción social de bienes básicos); crisis de valores (competencia e individualismo versus complementación y solidaridad). Conjunto de situaciones que se potencian entre sí hasta generar lo que hoy puede considerarse una profunda crisis civilizatoria. Pareciéramos estar inmersos en un proceso suicida impulsado por un modelo inviable y sin futuro.

Por otro lado emergen iniciativas sociales muy vigorosas que tienden a recolocar al ser humano $y$ la naturaleza al centro de nuestra ética, semillas de un nuevo proceso civilizatorio y de una cultura a la vez universal y respetuosa de la diversidad.

Procesos que conciben al mundo como espacio y patrimonio de todos y a nosotros, los seres humanos, como especie, entes sociales y personas en devenir que se perciben como sujetos activos y responsables en la construcción de una nueva sociedad en armonía con la naturaleza.

Esta nueva conciencia emergente, sustentada en múltiples experiencias innovadoras y transformadoras y en procesos crecientes de articulación de los afectados, se enfrenta a cuatro situaciones derivadas del proceso de globalización económica conducido por grandes intereses transnacionales, el capital financiero y sus aliados en los gobiernos y los medios de comunicación.

1. El empobrecimiento creciente de grandes masas de la población mundial, acompañado del despojo y destrucción de sus recursos: económicos, naturales y culturales. Hechos que están atrás del abandono del campo y de las migraciones masivas de impacto internacional.

2. La exclusión:

- Económica: la desposesión y la pobreza extrema;

- Social: la negación de los derechos económicos (al trabajo digno y bien remunerado) y sociales (a la alimentación, la salud, la vivienda y la educación de calidad);

- Política: la imposibilidad de incidir en las decisiones que nos afectan; la imposibilidad de participar y de ejercer los derechos ciudadanos;

- Cultural: la homogeneización impuesta como proyecto de dominación y mercadeo que destruye las culturas y formas de vida locales;

- Psicológica: la pérdida de la autoestima.

3. La expropiación de los haberes y saberes de los pueblos:

- De sus excedentes económicos;

- De los recursos existentes en sus territorios: el 
agua, la biodiversidad, los bosques y los recursos minerales y energéticos;

- De sus conocimientos y habilidades tecnológicas.

4. La destrucción de los colectivos mediante normas y prácticas que:

- Individualizan los problemas y las soluciones;

- Dividen a las comunidades;

- Destruyen las prácticas comunitarias;

- Atacan y buscan subordinar a los sindicatos, las organizaciones sociales, las cooperativas y los movimientos sociales a los intereses económicos y políticos de los poderosos.

En todos estos impactos juega un papel importante la manipulación ideológica y cultural. En consecuencia, y en la lucha por defender sus derechos, sus raíces, su ser mismo, los pueblos deben incluir la cultura como uno de los ámbitos estratégicos de acción, de resistencia y de construcción de alternativas.

En esta lucha del siglo XXI, jugará un papel relevante la construcción de una nueva cultura basada en:

- El reconocimiento y respeto de la diversidad cultural;

- La superación del aislamiento y la fragmentación (capaz de articular actores y solidaridades y de actuar desde sus raíces locales y en sus alcances globales);

- El manejo de lo cotidiano a partir del reconocimiento de la complejidad como nuevo paradigma.

Una nueva cultura capaz de actuar con eficacia contra la depredación de la naturaleza y la pérdida de soberanía social al impulsar niveles más altos de conciencia ecológica y de participación organizada en la democratización de la gestión pública.

\section{Contexto regional}

Los efectos del proceso de globalización económica y de las políticas neoliberales, que han promo- vido con eficacia los organismos financieros multilaterales y otros agentes vinculados a grandes intereses económicos transnacionales, han tenido un fuerte impacto en los procesos migratorios, la urbanización, la estructura y el crecimiento desordenado de las ciudades latinoamericanas.

La desregulación que redujo los controles y el papel de los organismos públicos que intervienen en la planeación y en diversas tareas del desarrollo urbano; la privatización de todos los insumos y procesos productivos del hábitat; la consecuente subordinación de los derechos sociales a los intereses y derechos mercantiles del capital inmobiliario y del financiero internacional; la fragmentación de las políticas públicas y la focalización de los apoyos estatales; el deterioro planificado de los salarios y de su capacidad adquisitiva; la cancelación de apoyos estatales a los enormes esfuerzos de los sectores populares por acceder a un lugar adecuado donde vivir y autoproducir su vivienda; la individualización de los problemas y de las soluciones que frena la producción social organizada y no lucrativa del hábitat... son expresiones de este impacto y constituyen factores que han llevado a concebir la vivienda como mercancía y las ciudades como paraíso para la especulación inmobiliaria.

El surgimiento reciente de regímenes de gobierno situados en el variopinto espectro de la izquierda latinoamericana ha llevado a cuestionar estos hechos $y$, en casos muy relevantes, a plantear opciones y generar instrumentos que rescatan lentamente el papel regulador del Estado y que abren posibilidades a la participación organizada de la sociedad en la gestión del desarrollo urbano.

\section{Temas estratégicos en la experiencia re- ciente latinoamericana}

Ante las tendencias, impactos y retos que genera la globalización económica son muchos los colectivos (redes, movimientos sociales, foros permanentes) que se plantean, tanto a nivel local como 
nacional o internacional, la necesidad urgente de poner en marcha experiencias transformadoras capaces de cimentar un cambio profundo que contribuya a construir un mundo para todos.

Desde esta perspectiva y con base en una larga experiencia de más de 40 años en el desarrollo de proyectos comunitarios de producción y gestión participativa del hábitat popular, se vienen impulsando en la región latinoamericana tres temas que se articulan entre sí para abrir nuevos cauces transformadores a la producción, gestión, uso y disfrute del hábitat humano:

- El derecho a la ciudad;

- La producción social del hábitat;

- La gestión participativa del hábitat.

\section{El derecho a la ciudad}

Este nuevo derecho concibe a la ciudad como un sistema complejo que incluye tanto el ámbito propiamente urbano como su entorno rural. Se plantea como un derecho colectivo y persigue como objetivo una ciudad incluyente, solidaria, equitativa, participativa, productiva, sustentable, habitable y disfrutable para todos.

El derecho a la ciudad se construye a partir de los siguientes fundamentos estratégicos:

- Ejercicio pleno de la ciudadanía. Es la realización de todos los derechos humanos y libertades fundamentales sin discriminación alguna, asegurando la dignidad y el bienestar colectivo, en condiciones de igualdad, equidad y justicia. Todas las personas tienen derecho de encontrar en la ciudad las condiciones necesarias para su realización económica, cultural, social y ecológica.

- Función social de la ciudad, de la tierra y de la propiedad. Se refiere principalmente a la distribución y la regulación del uso del territorio y el usufructo equitativo de los bienes, servicios y oportunidades que la ciudad ofrece, priorizando el interés público definido colectivamente.

- Gestión democrática de la ciudad. Implica la participación ciudadana en todos los espacios y has- ta el más alto nivel (decisión, control, cogestión) tanto en la formulación, implementación, seguimiento y evaluación de las políticas públicas como en la planeación, presupuestación y control de los procesos urbanos.

- Producción democrática de la ciudad y en la ciudad. Busca rescatar y fortalecer la capacidad productiva y la inserción de sus habitantes en la economía urbana, en especial de los sectores populares, fomentando la producción social del hábitat y el desarrollo de actividades económicas solidarias y capaces de consolidar un hábitat productivo.

- Manejo sustentable y responsable de los recursos naturales, patrimoniales y energéticos de la ciudad y su entorno. Persigue el uso socialmente responsable de los recursos. Implica el disfrute de todas las personas, comunidades o pueblos de un ambiente sano que les permita desarrollarse en igualdad de condiciones y busca garantizar que el desarrollo urbano no se realice a costa de las áreas rurales, de áreas de reserva ecológica, de otras ciudades y de las futuras generaciones.

- Disfrute democrático y equitativo de la ciudad. Busca el fortalecimiento de la convivencia social y el rescate, ampliación y mejoramiento de la función cultural, lúdica y recreativa del espacio público.

\section{La producción social del hábitat}

Por producción social del hábitat entendemos todos aquellos procesos generadores de espacios habitables, componentes urbanos y viviendas que se realizan bajo el control de autoproductores y otros agentes sociales que operan sin fines de lucro. Promueve las capacidades autogestivas y de decisión de los participantes y da prioridad al valor de uso por encima del valor mercantil de las construcciones y espacios que genera. ${ }^{1}$

\footnotetext{
${ }^{1}$ A partir de su promulgación en 2006 la Ley de Vivienda de México reconoce la producción social de vivienda en estos términos.
} 
Aquellas modalidades que se apoyan en procesos autogestionarios colectivos, por implicar capacitación, participación responsable, organización y solidaridad activa de los pobladores, contribuyen a:

- fortalecer las prácticas comunitarias, el ejercicio directo de la democracia, la autoestima de los participantes y una convivencia social más vigorosa;

- acrecentar la capacidad de gestión de los pobladores organizados y su control sobre los procesos productivos del hábitat;

- derramar recursos en la comunidad en que se desarrollan las acciones contribuyendo a potenciar la economía de los participantes, de la comunidad en que se ubican y de los sectores populares en su conjunto.

Al situar al ser humano, individual y colectivo, al centro de sus estrategias, su método de trabajo y sus acciones, pone en marcha procesos innovadores de profundo contenido e impacto transformador.

Al centrar las políticas de hábitat y los procesos de planeación, diseño y producción habitacional en la gente y no en el dinero, contiene el potencial de hacer de la vivienda y de los asentamientos rurales y barrios populares productos socio-culturales que reconocen tanto la diversidad y la riqueza creativa y de vida de las comunidades como el valor de respetar las trazas urbanas históricas, formas de vida, aspiraciones y sueños de los grupos sociales implicados.

\section{Gestión participativa del hábitat}

La experiencia social y participativa de un colectivo en la producción de su hábitat abre amplias posibilidades para mantener y profundizar la organización comunitaria durante la fase de uso del conjunto habitacional o del asentamiento construido.

Por gestión participativa del hábitat entendemos la acción consciente y responsable de la comunidad organizada en la administración, mantenimiento, uso y mejoramiento de los espacios públicos y de los equipamientos colectivos. Implica la interacción corresponsable con los organismos públicos encargados de proporcionar los servicios y una amplia participación en las decisiones referentes a la planeación y ejecución de nuevos proyectos y actividades destinadas a mantener y mejorar la calidad de vida del colectivo.

Contempla también la formación permanente de sus integrantes, la organización de actividades culturales y deportivas, el desarrollo y administración de proyectos productivos y ambientales, la realización conjunta de actividades colectivas que garanticen la convivencia, la seguridad y el desarrollo personal y comunitario de todos los integrantes de la comunidad y su vinculación solidaria y activa con otras comunidades y con su entorno social.

\section{Hacia una experiencia integradora en Mé- xico}

En la Ciudad de México, por iniciativa de organizaciones del movimiento urbano popular, venimos perfilando y promoviendo ante el gobierno de la ciudad varias iniciativas que buscan por un lado la elaboración y suscripción de la Carta de la Ciudad de México por el Derecho a la Ciudad y por otro la realización de un programa demostrativo de producción y de gestión social del hábitat.

Ambas iniciativas están articuladas y se impulsan y negocian en forma paralela, contando con la acción promotora de varios actores:

- Integrantes de las organizaciones urbanas populares;

- Funcionarios del gobierno de la Ciudad;

- Organizaciones civiles de apoyo técnico;

- La oficina para América Latina de la Coalición Internacional para el Hábitat.

$\mathrm{Y}$, adicionalmente, en el caso de la Carta:

- La Comisión de Derechos Humanos del Distrito Federal (ombudsman capitalino); 
- El espacio de Derechos Económicos, Sociales y Culturales (red civil autónoma de derechos humanos).

El gobierno de la ciudad reconoce ambas propuestas como iniciativas de la sociedad civil organizada y las apoya activamente en diversas formas.

Tanto el proyecto de la Carta como el de producción y gestión social del hábitat tienen como propósito último contribuir, mediante procesos y prácticas sociales, alternativos a la lógica del lucro, a la construcción de condiciones en las que prive la solidaridad, la justicia, la democracia ejercida desde la base popular y la interacción sustentable con la naturaleza.

\section{La Carta de la Ciudad de México por el De- recho a la Ciudad}

El proyecto que se viene conformando y debatiendo concibe a la ciudad y su entorno rural como un sistema complejo en el que todas sus partes están correlacionadas: los factores socio-culturales, los económico-laborales y los físico-ambientales.

No se limita a considerar la ciudad como un espacio físico a planificar con propósitos económicos modernizante para hacerla competitiva globalmente; se parte de un nuevo paradigma centrado en las personas y comunidades diversas que habitan su territorio y en la viabilidad ecológica y económica de ese conglomerado en el corto y largo plazos.

Busca estimular la participación activa de la sociedad organizada en el mejoramiento de sus condiciones de vida y en la activación de los cambios que es necesario impulsar para construir una ciudad justa, viable y disfrutable para todos.

Se trata de cambios que desde el corto plazo mejoren la vida de los habitantes de la ciudad, principalmente la de los más débiles y vulnerables, y que no pongan en riesgo la calidad de vida de las generaciones futuras, lo que necesariamente implica un uso más racional y una mejor distribución social de los recursos.

La siguiente matriz (Figura 1) sintetiza estos propósitos al correlacionar el perfil de la ciudad que queremos con los fundamentos estratégicos del derecho a la ciudad esbozados más arriba.

Los renglones de la matriz expresan las aspiraciones sociales, las columnas, los campos de intervención pública y acción social organizada que es necesario activar para concretarlas.

Los nodos de la matriz identifican los cruces estratégicos a considerar en la formulación de los planes y programas y aquellos que definen campos de intervención complementarios o de apoyo. También implican la interacción dialéctica entre la sociedad organizada y los poderes públicos. Interacción necesaria para garantizar la apropiación social de los procesos de cambio y su conducción corresponsable entre ciudadanía y gobierno.

En la matriz, en tanto expresión del derecho a la ciudad como sistema complejo, podemos colocar cualquier tema $\mathrm{o}$ actividad que tenga un impacto territorial para encontrar sus correlaciones con otros campos de actividad y con la ciudad en su conjunto.

De hecho la matriz puede verse como un holograma en el que su observación desde cualquier ángulo nos conduce a visualizar su correlación con el conjunto.

En la formulación de la Carta de la Ciudad de México por el Derecho a la Ciudad hemos optado por ordenar su parte sustantiva a partir de la ciudad que queremos, esto es, de los renglones. Así al cruzar con la primera columna (Ejercicio pleno de la ciudadanía), cada aspiración social se traduce en derechos (existentes y por conquistar), para después avanzar, en las demás columnas, en la identificación de las acciones que es necesario implementar, en diversos campos de la gestión urbana, para viabilizar su ejercicio y garantizar progresivamente su cumplimiento. 


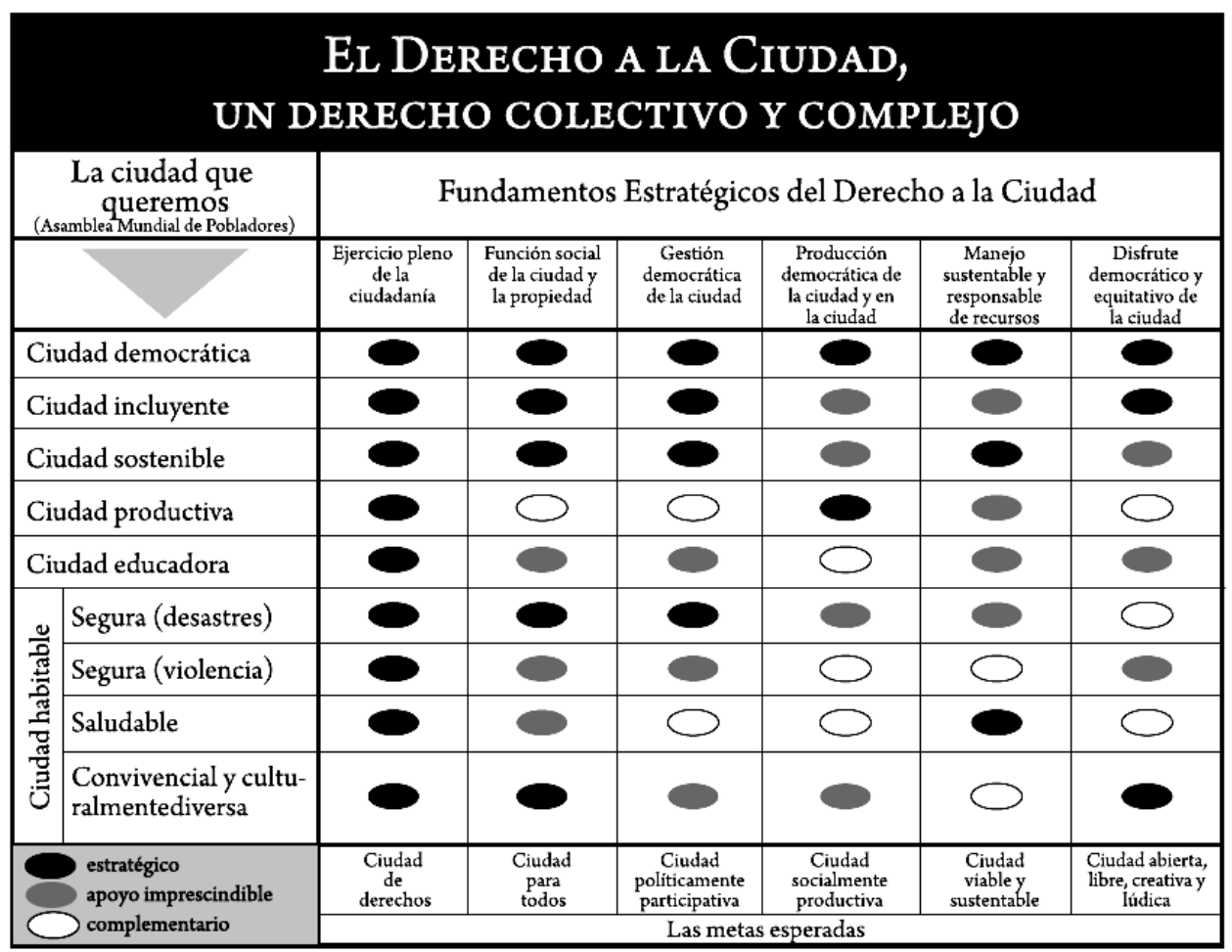

Figura 1: El Derecho a la ciudad, un derecho complejo. Fuente: Elaboración propia.

La carta no se concibe como un programa, sino como una guía de navegación a largo plazo. En ella se incluyen compromisos de los diversos actores para avanzar en su implementación. Se espera que sea firmada este año por el gobierno de la ciudad y los demás actores y que se le dé peso de ley para impulsarla.

\section{El Proyecto Comunitario de producción y gestión social del hábitat}

En forma paralela pero articulada por los mismos actores que promueven la carta, se trabaja en el diseño y gestión ante las autoridades de la ciudad de un proyecto que busca aplicar los contenidos del Derecho a la Ciudad a un conjunto de iniciativas comunitarias encaminadas a la producción y gestión de unidades habitacionales en la Ciudad.

El proyecto se plantea como un proceso de contenido transformador que tiene como objetivos:

- Integrar procesos organizativos y formativos de alto nivel participativo;

- Coadyuvar a construir organización social y ciudadana;

- Contribuir a la gestión democrática de la ciu- dad y al manejo sustentable de los recursos económicos y ambientales;

- Mejorar la calidad de vida y la convivencia social tanto a lo interno de los conjuntos habitacionales como en su entorno;

- Fortalecer la economía barrial y la de los participantes;

- Generar una nueva cultura solidaria y de apoyo mutuo;

- Rescatar el sentido de pertenencia e identidad social.

Frente a las tendencias que se plantean al inicio de este texto, el proyecto se propone fortalecer la capacidad productiva y de gestión de los sectores populares para que sean capaces de enfrentar con mayor eficacia el embate de los grandes intereses económicos e inmobiliarios que pretenden expropiar sus saberes, frenar sus iniciativas autónomas e incluso desalojarlos (Figura 2).

Para alcanzar estos objetivos, el proyecto se estructura en torno a propuestas alternativas a las tendencias que hoy se imponen desde los centros de poder corporativo que operan la globalización económica. 


\begin{tabular}{|c|c|}
\hline Frente a las tendencias a: & El proyecto plantea: \\
\hline La exclusión social & $\begin{array}{l}\text { El desarrollo de procesos incluyentes que reconozcan e } \\
\text { incorporen la pluralidad e impidan la discriminación }\end{array}$ \\
\hline La competencia a ultranza & La solidaridad y la ayuda mutua \\
\hline El individualismo y la destrucción de los colectivos & $\begin{array}{l}\text { La prevalencia de la organización, la comunidad y lo co- } \\
\text { lectivo }\end{array}$ \\
\hline La homogeneización y el reduccionismo & $\begin{array}{l}\text { El respeto y el fomento a la diversidad cultural y de op- } \\
\text { ciones que de ella se derivan }\end{array}$ \\
\hline $\begin{array}{l}\text { El control autoritario y la imposición de formas de convi- } \\
\text { vencia urbana }\end{array}$ & La gestión participativa y democrática del hábitat \\
\hline $\begin{array}{l}\text { La pasividad y la dependencia que generan las políticas } \\
\text { compensatorias de la pobreza }\end{array}$ & $\begin{array}{l}\text { La inserción informada, productiva y responsable de los } \\
\text { pobladores en la planeación, producción y gestión de su } \\
\text { hábitat }\end{array}$ \\
\hline La producción mercantil de la ciudad y de la vivienda & $\begin{array}{l}\text { La producción y la gestión social no lucrativa de la vi- } \\
\text { vienda y el hábitat }\end{array}$ \\
\hline $\begin{array}{l}\text { La apropiación individual o corporativa privada del suelo y } \\
\text { otros bienes comunes }\end{array}$ & $\begin{array}{l}\text { La apropiación, uso y gestión colectiva del suelo, de los } \\
\text { espacios públicos y de otros bienes comunes }\end{array}$ \\
\hline $\begin{array}{l}\text { El consumismo hegemónico y la mercantilización de todos } \\
\text { los satisfactores humanos }\end{array}$ & $\begin{array}{l}\text { La producción, distribución y consumo basado en princi- } \\
\text { pios económicos solidarios }\end{array}$ \\
\hline El deterioro ambiental y la depredación de la naturaleza & $\begin{array}{l}\text { La sustentabilidad ambiental, el uso responsable de los } \\
\text { recursos y la interacción respetuosa con la naturaleza }\end{array}$ \\
\hline $\begin{array}{l}\text { El manejo sectorizado y especializado de los componentes } \\
\text { del hábitat por los gobiernos o la empresa privada }\end{array}$ & $\begin{array}{l}\text { La gestión integral del hábitat por y desde la comunidad } \\
\text { organizada en vinculación con programas públicos mu- } \\
\text { tuamente aceptados }\end{array}$ \\
\hline $\begin{array}{l}\text { La imposición de modelos de intervención tecnocráticos y } \\
\text { de prototipos únicos }\end{array}$ & $\begin{array}{l}\text { La planeación y el diseño participativo de opciones ade- } \\
\text { cuadas a circunstancias y procesos sociales específicos }\end{array}$ \\
\hline
\end{tabular}

Figura 2: Alternativas que caracterizan al Proyecto Comunitario de Inclusión en la Ciudad. Fuente: Elaboración propia.

En base a estos lineamientos y a los fundamentos estratégicos de la Carta por el Derecho a la Ciudad, se formuló un documento que detalla las características del proyecto, las acciones necesarias para concretarlo y los compromisos que asumen las personas, las familias y las organizaciones interesadas en ser parte de esta iniciativa algunas con más de 2.000 participantes.

Más de veinte organizaciones sociales están involucradas a este proceso estudiando y debatiendo el documento, organizando su ahorro y sus comisiones de trabajo, conociendo a fondo sus condiciones, posibilidades y capacidades y negociando con las autoridades su acceso a suelo adecuado y a los apoyos necesarios para realizar sus respectivos proyectos.

\section{Algunos referentes históricos de la propuesta}

Estos lineamientos se fundamentan en múltiples experiencias concretas ya realizadas en América Latina y particularmente en México. Experiencias complejas que hemos venido registrando y sistematizando, $^{2}$ y que incluyen varios de los componentes y lineamientos mencionados. En los Cuadros recogidos como anexos se presenta una sín-

\footnotetext{
${ }^{2}$ Con motivo del Foro Universal de las Culturas y del Foro Urbano Mundial, realizados en Barcelona, en 2004, HIC reunió y sistematizó 45 casos regionales de producción y gestión social del hábitat y publicó un libro en el que se presenta este trabajo y fichas de otras regiones del planeta (Ortiz, E. y Zárate, L. De la marginación a la ciudadanía. Barcelona: Hábitat Internacional Coalition / Forum Barcelona, 2004).
} 
tesis de tres de estos casos.

El primero de ellos, la Cooperativa Unión de Palo Alto, constituye un caso emblemático de lucha por el derecho a la Ciudad y el primer proyecto de producción y gestión social de un conjunto habitacional cooperativo en la Ciudad de México. Por la situación económica precaria de esta comunidad y por la falta de instrumentos financieros programáticos y administrativos adecuados a esta forma de producción, se trata de un conjunto que se desarrolló en forma progresiva durante varios años.

Esta y otras experiencias rurales y urbanas que se realizaron a finales de los años 60 y la primera mitad de los años 70, fueron referente importante en la formulación de las políticas, estrategias e instrumentos que se integraron en el primer Programa Nacional de Vivienda decretado en 1979. Una de las decisiones importantes que se derivaron de este Programa fue la creación del Fondo Nacional de Habitaciones Populares (FONHAPO), organismo encargado de financiar la vivienda de los sectores de más bajos ingresos del país, incluyendo en forma prioritaria a los autoproductores organizados.

El segundo y tercer casos, Cananea y el Capulín, desarrollados varios años más tarde, contaron ya con apoyos y financiamientos institucionales, lo que facilitó y acortó en mucho, pese a su complejidad, los tiempos de realización de estos conjuntos.

Se trata en los tres casos de proyectos entre los 20 y 35 años de existencia que, a pesar de múltiples problemas que han debido enfrentar para desarrollarse en un ambiente hostil, se mantienen organizados y en constante proceso de mejoramiento. Estas y muchas otras experiencias muestran la validez del planteamiento y el interés que hoy moviliza a muchas organizaciones sociales y otros actores a reivindicar la producción social del hábitat como un sistema que cuente con los instrumentos y apoyos financieros y técnicos necesa- rios para desarrollarse.

Hoy buscamos que estas experiencias puntuales, muchas de ellas premiadas por diversos organismos como "mejores prácticas", sirvan como referente para impulsar, conjuntamente con los movimientos sociales urbanos y otros actores opuestos a las políticas mercantiles y homogeneizantes del neoliberalismo, no solo la realización de este proyecto demostrativo sino la instauración de un sistema público de apoyo a la producción social y a la gestión participativa del hábitat.

\section{Consideraciones finales}

La magnitud de las carencias sociales y la urgencia de dar soluciones a corto plazo son consideraciones que orientan las decisiones mercantiles y políticas hacia soluciones tecnocráticas, generalmente masivas y repetitivas, que buscan la eficiencia y que ignoran los factores sociales y culturales que dan sentido, diversidad y condiciones de convivencia a nuestras ciudades.

¿Cómo resolver las contradicciones que impiden que la producción y la gestión participativa del hábitat rural y urbano formen parte de las políticas de desarrollo urbano y regional?

¿Cómo acotar los tiempos y darle escala a esta forma de producción y de gestión del hábitat?

No es ciertamente haciendo más de lo mismo, imponiendo modelos cerrados de intervención ni reproduciendo masivamente unos cuantos prototipos y grandes conjuntos de casas o departamentos.

Los caminos para abrir cauce a esta nueva forma de producción y gestión del hábitat rural y urbano, darle escala y eficacia, pasan por:

- Reconocer el enorme potencial que esta forma de producción y gestión social del hábitat tiene en la construcción de ciudadanía activa y responsable, de una economía popular más fuerte, de condiciones ambientales más sanas y viables a largo plazo, de ciudades incluyentes, seguras, habitables y disfrutables. 
- Diseñar y operar un sistema articulado de instrumentos de apoyo, jurídicos, financieros, administrativos, de inducción y de fomento organizativo y tecnológico que faciliten su desarroIlo.

- Impulsar un sistema abierto y flexible de opciones programáticas que permitan responder a la diversidad de condiciones, iniciativas y formas organizativas de la población participante.

- Operar un sistema permanente de formación y capacitación de los diversos actores involucrados, dando atención prioritaria a los aspectos socio-organizativos y a la construcción de una nueva cultura cimentada en la solidaridad, la confianza y la ayuda mutua.

- Generar mecanismos participativos de planeación, seguimiento y evaluación que permitan acumular experiencia y retroalimentar los procesos.

- Abrir espacios de interlocución y gestión corresponsable Estado-sociedad organizada, para facilitar y revisar permanentemente la aplicación de las políticas y la operación de los programas.

La implementación de estos y otros instrumentos y espacios participativos permitirá que el gran desafío cuantitativo a resolver no dependa solo de la producción masiva de grandes unidades habitacionales homogéneas sino de la multiplicación de iniciativas sociales urbanas y habitacionales muy diversas.
El reto es no sistematizar los productos (viviendas, conjuntos, equipamientos, trazos urbanos) sino los procesos de gestión de los organismos públicos para hacerlos capaces de administrar con eficacia la complejidad. Tenemos hoy las herramientas necesarias para hacerlo.

Ciudades y pueblos rurales más habitables y sustentables, una mayor diversidad de propuestas urbanas y arquitectónicas, procesos participativos más vigorosos y propositivos, comunidades mejor organizadas, mayores oportunidades de convivencia social y de fortalecimiento comunitario en lo formativo, lo económico y lo cultural y cambios estratégicos en las políticas públicas son algunos de los resultados que es posible esperar de estos procesos.

Cita del artículo:

ORTIZ Enrique. Derecho a la ciudad, producción social y gestión participativa del hábitat. La promoción de iniciativas comunitarias incluyentes en la Ciudad de México. Hábitat y Sociedad, 2010, no 1, p. 55-70. $<$ www.habitatysociedad.us.es $>$.

http://dx.doi.org/10.12795/HabitatySociedad.2010.i1.04 


\section{Anexos: Cuadros}

\section{Cuadro 1. Cooperativa de Vivienda "Unión de Palo Alto"}

Ubicación: Km. 14.5 de la carretera México-Toluca. Cuajimalpa, Distrito Federal.

\section{Antecedentes}

La comunidad de Palo Alto se origina en la explotación de unas minas de arena en la periferia de la Ciudad de México, por un grupo de migrantes del campo. Además de los bajos salarios que percibían, eran obligados a arrendar un pedazo de tierra para construir con sus propios medios, viviendas provisionales, mismas que en caso de dejar el trabajo pasaban a ser propiedad del dueño de las minas.

A principios de los años 70, al terminarse la explotación de las minas (35 años después de haberse iniciado), la zona de Palo Alto quedó rodeada por asentamientos residenciales de lujo y el dueño trató de erradicar a sus antiguos trabajadores, con miras a cambiar el uso del suelo, aprovechando la magnifica ubicación de los terrenos de Palo Alto.

Es entonces que los vecinos se organizan e inician una larga lucha para no ser expulsados a zonas periféricas más alejadas y menos habitables.

\section{Tamaño de la población participante y beneficiaria}

Doscientas treinta y siete familias fueron las originarias de la cooperativa, la cual actualmente cuenta con aproximadamente 2.500 habitantes.

\section{Aspectos innovadores}

En lo socio-organizativo, Palo Alto fue la primera cooperativa de vivienda registrada en el DF, la primera en plantearse la propiedad cooperativa (la propiedad del conjunto habitacional es de la cooperativa, la cual establece un contrato de uso con sus socios) y la primera en plantear un concepto integral de los diferentes aspectos que constituyen un asentamiento humano.

\section{Componentes del programa o proyecto (breve caracterización de cómo se articulan). Viviendas, servicios y equipamientos}

El primer paso fue resolver la amenaza de desalojo y adquirir la tierra. Las viviendas se construyeron por razones estratégicas antes que los servicios y equipamientos. Una vez construida la primera fase de viviendas, se fueron introduciendo poco a poco las redes de alcantarillado y de agua potable, pavimento de las calles y la electricidad.

Ya consolidado el asentamiento, se construyó una cancha de fútbol, una biblioteca, la capilla de la colonia, se gestionó la construcción de una escuela ubicada en la cercanía, una lechería, una unidad de planificación familiar, un consultorio médico (el cual por falta de presupuesto de la delegación ahora funciona sólo como dispensario), juegos infantiles y además una casa se destinó para funcionar como jardín de niños. También se construyó una bodega para la cooperativa, el salón de asambleas, la tortillería, la tienda, la extinta productora de tabiques y recientemente se construyó con la colaboración del actual Gobierno del Distrito Federal un salón de usos múltiples, un área de cómputo con acceso a Internet para los jóvenes y un gimnasio.

Además se reservó un área para construir departamentos para los hijos de los socios, una parte de este proyecto ya fue construida y está habitada. 


\begin{abstract}
Aspectos sociales y culturales
La participación de los habitantes ha sido muy importante, y en particular de las mujeres, quienes a lo largo del proceso siempre han sido muy participativas, incluso son ellas las que más asisten a las asambleas.

En los aspectos educativos se han realizado campañas internas de alfabetización, se participa en los problemas de escolarización de los niños y adolescentes y se realiza un trabajo permanente de educación cooperativa. Asimismo, se han organizado en distintos momentos grupos de teatro con miembros de la comunidad, que han representado momentos importantes de su historia para fortalecer su identidad entre las nuevas generaciones.

En el campo de la salud, se ha trabajado tanto en la atención directa como en la prevención a través de campañas de mejoramiento ambiental, higiene y nutrición.

Por decisión de la asamblea se organizó una comisión juvenil que trabaja con los varios cientos de jóvenes y adolescentes de la comunidad.

Fortalecimiento económico de los participantes y/o sustentabilidad ecológica

Durante el proceso se han creado distintas actividades y empresas generadoras de ingresos, entre ellas una tienda de la cooperativa, una tortillería y, durante la construcción, una productora de tabiques y un taller de herrería para la construcción de las casas. Las ganancias se aplican a obras de beneficio común de la cooperativa; además de generar empleos para algunos miembros de ésta.

En la fase de construcción los habitantes eran contratados para realizar tareas de albañilería, electricidad, plomería, herrería y otros oficios, recibiendo un sueldo por su trabajo.
\end{abstract}

\title{
Contribución al desarrollo urbano
}

Esta experiencia, además de articularse en distintos proyectos de desarrollo y mejoramiento urbano orquestados por las autoridades de la ciudad, constituye un caso paradigmático de la lucha por el Derecho a la Ciudad.

\section{Logros y principales lecciones aprendidas}

\section{Principales impactos}

La organización cooperativa ha demostrado ser un instrumento eficaz para el logro de resultados concretos tanto para el propio grupo como para el impulso de esta forma de enfocar la acción habitacional en el país.

Algunos de los logros más significativos han sido:

- El abaratamiento de los costos de producción de su vivienda, al permitirles adquirir la tierra más barata, comprar en forma masiva sus materiales, producir componentes de sus viviendas, racionalizar su construcción y realizar diversas tareas relacionadas con la gestión y administración de los proyectos y las obras.

- Reforzamiento de la economía del grupo al generarse fuentes internas de trabajo.

- Superación de problemas sociales arrastrados por varias décadas: analfabetismo, insalubridad, alcoholismo, pasivismo, desintegración familiar.

- Canalización de asesoría técnica, vinculada directamente a la cooperativa en los campos social, financiero, arquitectónico, urbanístico, administrativo y contable, lo que ha permitido un manejo creciente de conocimientos técnicos en estos campos por los propios cooperativistas. 


\section{Cuadro 2. Cananea: Producción y gestión social de un barrio}

Ubicación: Predio El Molino, Iztapalapa, México D.F., México.

\section{Breve descripción del caso}

Experiencia orientada a mejorar las condiciones de vida de familias de escasos recursos a través de programas de autoproducción de vivienda, abasto, salud, nutrición y de actividades educativas, ecológicas, culturales, deportivas, infantiles y juveniles, principalmente con las mujeres de la comunidad.

\section{Antecedentes}

A principios de 1983, cuatro grupos de solicitantes se organizan a partir de la necesidad común de vivienda digna, para responder a la oferta de Fonhapo para desarrollar un conjunto de 2.000 viviendas, mediante procesos de producción social organizada, en el predio El Molino, propiedad de este organismo.

Uno de los grupos participantes se conformó legalmente como Unión de Colonos, Inquilinos y Solicitantes de Vivienda (UCISV-Libertad A.C.). Sus integrantes fomentaron el ahorro para pagar el enganche del terreno e iniciaron la gestión de un crédito con el Fondo Nacional de Habitaciones Populares (FONHAPO), para financiar la adquisición de una parte del predio y la autoproducción de 1.087 viviendas.

\section{Tamaño de la población participante y beneficiada}

En forma directa, las 1.087 familias integradas al proyecto Cananea. Otras 1.000 familias en los restantes tres grupos participantes y miles de habitantes en el entorno del Predio El Molino que no contaban con servicios ni urbanización.

\section{Aspectos innovadores}

El proyecto maneja innovaciones principalmente en lo socio-organizativo y en lo tecnológico. Destaca la articulación que se da entre gestión social, producción del hábitat, mejoramiento ambiental y fortalecimiento económico.

\section{Componentes del proyecto (breve descripción de cómo se articulan)}

El proyecto incluye, en cuanto al hábitat, adecuaciones del suelo, construcción de vivienda progresiva (primera etapa $54 \mathrm{~m}^{2}$ y otro tanto previsto para crecimiento futuro), urbanización, saneamiento alternativo y espacios recreativos, culturales, educativos y productivos.

En cuanto al componente social, se alcanzó un alto nivel de participación, organización y autonomía del grupo. Desde el inicio, la comunidad ejerció el control del proceso y tomó las decisiones; administró los recursos provenientes tanto de aportaciones externas y de crédito como de la movilización de diversos activos de la propia comunidad; realizó la negociación con los demás actores y definió sus planes de acción.

Además, participó organizadamente en la formación de sus miembros y en la autoconstrucción de sus viviendas, con recursos y trabajo en la adecuación del terreno, en la urbanización y en la habilitación de espacios públicos. Posteriormente ha venido gestionando escuelas, iglesias, mercados, deportivos, biblioteca, centros culturales, cocinas populares y estancias infantiles.

De esta manera, se instalaron y desarrollaron proyectos de vivienda para más de mil familias que hoy cuentan con una vivienda digna, comedores y desayunadores comunitarios, centros de desarrollo infantil, 
manejados por madres de familia de la misma comunidad, espacios de atención a la salud y de capacitación de promotoras en salud alternativa. Recientemente (2008) esta y las otras 3 organizaciones que habitan en El Molino han habilitado cuatro áreas comunitarias baldías para el cultivo de hortalizas, contribuyendo así a mejorar la alimentación y la economía de las familias participantes y las condiciones ambientales de la zona.

A partir de experiencias como ésta, la organización social replicó este proyecto en otros lugares donde ha desarrollado proyectos de educación abierta en primaria y secundaria para personas que trabajan. Ha instalado bibliotecas comunitarias con espacios de trabajo con niños, jóvenes y adultos, en donde además de la consulta bibliográfica se les ayuda y orienta en las tareas. Además, hoy cuenta con espacios culturales donde se promueven actividades de danza, baile de salón, rescate de costumbres culturales de la comunidad; talleres de serigrafía, mimbre, cestería, chocolate artístico, arte con semillas, así como de prevención de SIDA y contra las adicciones, sexualidad, autoestima, defensoría de los derechos de los niños y los jóvenes, etc.

Han construido parques ecológicos y rescatado áreas verdes en diferentes colonias, instalando canchas deportivas y áreas de juegos infantiles. También han promovido talleres para reciclar y reutilizar desechos de plástico, papel y vidrio.

\section{Aspectos organizativos}

La organización opera bajo la forma legal de Asociación Civil, con asambleas por manzana que se reúnen cada ocho días y por sección cada mes, donde se deciden las soluciones a los problemas y se informa a las comisiones de Organización, Finanzas, Técnica, Cultura y Prensa, Ecología, Honor y Justicia, Mujeres, Abasto y Salud.

Las decisiones se toman, según el tipo de asunto, por consenso o por votación, para dar agilidad y legitimidad a los procesos. La asamblea conduce y da seguimiento a los procesos y analiza las cuentas que rinden los responsables de cada actividad.

\section{Logros y principales lecciones aprendidas}

Para las mujeres fue una experiencia nueva, fue un triunfo y un logro personal y colectivo.

Los resultados del proyecto han tenido impacto en otras experiencias y tienen un alto potencial para promover cambios en las políticas públicas.

La inserción de esta experiencia innovadora en la zona, ahora muy poblada, y el hecho de estar junto con otras organizaciones fraternas en el predio, tiene una gran significación urbana, al constituirse en una experiencia de alto impacto en temas como la producción social del hábitat, la gestión democrática de la ciudad y la sustentabilidad ambiental y económica en comunidades de bajo ingreso. 


\section{Cuadro 3. Conjunto Autogestionario El Capulín}

Ubicación: Naucalpan de Juárez, Estado de México, México.

\section{Antecedentes:}

Un grupo de obreros, empleados, artesanos y comerciantes ambulantes de bajos ingresos integraron, en 1988, la sección Tierra y Libertad de la Unión de Colonos, Inquilinos y Solicitantes de Vivienda Libertad (UCISV-Libertad), organización social que para esas fechas había promovido varios proyectos habitacionales.

UCISV-Libertad recurrió al Fondo Nacional de Habitaciones Populares (FONHAPO) para gestionar un terreno de su propiedad denominado "El Capulín" y crédito para adquirirlo, urbanizarlo y para la edificación de 163 viviendas.

\section{Tamaño de la población participante y beneficiaria:}

En forma directa, 163 familias, alrededor de 1.000 habitantes; indirectamente miles de habitantes en el entorno de El Capulín y aguas abajo del arroyo que limita el predio en uno de sus lados.

\section{Aspectos innovadores}

El proyecto maneja innovaciones principalmente en lo socio-organizativo y en lo tecnológico. Destaca la articulación que se da entre gestión social, producción del hábitat, mejoramiento ambiental y fortalecimiento económico.

\section{Componentes del proyecto (breve descripción de cómo se articulan)}

El proyecto incluyó, en cuanto al hábitat, adquisición y adecuación del suelo, construcción de vivienda progresiva (primera etapa $53 \mathrm{~m}^{2}$ y otro tanto previsto para crecimiento futuro), urbanización, saneamiento alternativo y espacios productivos.

Se estableció inicialmente una escuela primaria autogestionada para 420 alumnos (12 grupos), construida provisionalmente por la comunidad. Desde noviembre de 2005 cuentan con un nuevo edificio de 14 aulas, laboratorio, biblioteca y aula de cómputo. Cuentan también con espacios adaptados para atención de preescolares y un club de la tercera edad, y reserva para áreas verdes, salón comunal y capilla.

En cuanto al componente social, se han alcanzado altos niveles de participación, organización y autonomía del grupo. Desde sus primeros pasos la comunidad ejerce el control del proceso y de las decisiones; administra los recursos provenientes tanto de aportaciones externas y de crédito como de la movilización de diversos activos de la propia comunidad; realiza la negociación con los demás actores y define sus planes de acción.

Aunque por restricciones del organismo financiero se le impidió participar en tareas de autoconstrucción de sus viviendas, la comunidad participó organizada y activamente con recursos y trabajo en la adecuación de su terreno y la construcción de los muros de contención, la infraestructura alimentadora de agua al conjunto, las redes que alimentan la planta de tratamiento, la propia planta y el invernadero, las guarniciones y aceras del conjunto y la escuela provisional.

En el proceso participativo destaca el papel de las mujeres como principales conductoras del proceso, de la larga lucha para hacerlo posible y del proyecto productivo.

Dos componentes articulados dentro del proyecto son el ecológico y el económico. La planta de trata- 
miento de aguas grises y negras permite obtener al final de un proceso de descomposición anaeróbica y de filtraje biofísico aguas para riego. Esto llevó a construir y operar un invernadero que la comunidad destinó al cultivo comercial de flores, generando además excedentes económicos para la organización, un empleo en el mantenimiento de la planta y 20 potenciales en los cultivos. Existen cisternas individuales captadoras de agua pluvial en las viviendas que apoyan la operación de la planta y ahorran costos.

En cuanto a su impacto urbano, además de la contribución a la sustentabilidad ambiental de la zona, el proyecto incluyó la donación de un espacio para la escuela y para equipamiento deportivo que atiende necesidades barriales y constituye un ejemplo de alto impacto visual y organizativo en su entorno.

El componente aglutinador de esta experiencia son los procesos de capacitación, organización y gestión participativa del conjunto de componentes y procesos.

\section{Aspectos organizativos}

La organización opera bajo la forma legal de asociación civil, se estructura a nivel vecinal por cuadras y actúa en base a comisiones permanentes como las de abasto, técnica, ecológica, finanzas, salud, educación, cultura, deporte, prensa y propaganda, política, honor y justicia, archivo.

Se organizan también brigadas que integran personas de las diferentes comisiones. Ambas informan de sus actividades a la comunidad cada 8 días en asambleas que se realizan desde hace 20 años los domingos.

Las decisiones se toman, según el tipo de asunto, por consenso o por votación para dar agilidad y legitimidad a los procesos. La asamblea conduce y da seguimiento a los procesos y recibe y analiza las cuentas que rinden los responsables de cada actividad.

La comunidad ha movilizado diversos recursos sociales y financieros: ahorro, mano de obra, materiales y la gestión. Obtuvo fondos públicos para el financiamiento del conjunto habitacional y, para la construcción de la planta, recurrió a una combinación de recursos de crédito y a fondo perdido tanto federales como estatales y municipales.

\section{Logros y principales lecciones aprendidas}

Además de haberse producido las 163 viviendas y de construir y de manejar la escuela primaria, se cuenta a la fecha con la planta de tratamiento, el invernadero y otros equipamientos operando.

La planta, además de proteger el medio ambiente, ya que no utiliza químicos, protege el manto freático, recupera recursos utilizados en el cultivo, utiliza poco espacio (160 $\left.\mathrm{m}^{2}\right)$ y no gasta energía.

Se ha dado un alto impacto en la vida de las mujeres participantes en el proceso (este caso fue escogido para su registro en un video internacional presentado en Hábitat II).

La comunidad ha crecido mucho, no sólo por haber logrado sus objetivos habitacionales sino por el desarrollo de su capacidad negociadora y de gestión de un barrio y de un sistema de manejo de agua. Se fortalece la economía de la comunidad y se desarrolla la conciencia ecológica del grupo y se abren con ello nuevas perspectivas. 